Original Article

\title{
COMPARATIVE QUANTITATIVE PHYTOCHEMICAL ANALYSIS OF THE LEAVES OF SENNA ITALICA COLLECTED FROM DIFFERENT AREAS IN LIMPOPO PROVINCE, SOUTH AFRICA
}

\author{
S. S. GOLOLO ${ }^{1}$, N. S. MAPFUMARI ${ }^{2}$, M. A. MOGALE ${ }^{3}$
}

${ }^{1}$ Senior Lecturer of Biochemistry, School of Science and Technology, Sefako Makgatho Health Sciences University, South Africa, ${ }^{2}$ PhD Candidate in Pharmaceutical Chemistry, School of Pharmacy, Sefako Makgatho Health Sciences University, South Africa, ${ }^{3}$ Biochemistry, School of Science and Technology, Sefako Makgatho Health Sciences University, South Africa Email: Stanley.gololo@smu.ac.za

Received: 05 Oct 2017 Revised and Accepted: 21 Dec 2017

\section{ABSTRACT}

Objective: The current study was aimed at comparative quantitative phytochemical analysis of the leaves of S. italica collected from four districts in Limpopo province, South Africa, in order to establish whether geographical location have an effect on the accumulation of phytochemicals within the leaves of the plant species under study.

Methods: The leaves of S. italica were collected from four districts in Limpopo province of South Africa namely; Capricorn, Sekhukhune, Vhembe and Waterberg districts, dried, ground to powder and extracted using different organic solvents. The extracts of the leaf samples from different locations were subjected to quantitative phytochemical analysis for total phenolic content, total tannin content, total flavonoid content and total saponin content using spectrophotometric measurements. The resultant quantities were analysed for statistical differences.

Results: The leaf samples of $S$. italica from the four districts in Limpopo province showed significant differences $\left({ }^{*} p<0.05\right)$ in their phytochemical quantities, with main data expressed as mean $\pm S \mathrm{~S}$. Total phenolic content was in highest amounts in leaf samples from Waterberg district compared to samples from other districts. Total tannin content was in highest amounts in the Vhembe district leaf samples compared to samples from other districts. Total flavonoid content was in highest amounts in the leaf samples from Waterberg district compared to samples from other districts. Total saponin content was in highest amounts in the Vhembe district leaf samples compared to samples from other districts.

Conclusion: The findings of the study thus suggest that geographical location has an effect on the accumulation of phytochemicals in the leaves of $S$. italica.

Keywords: Medicinal plants, Phytochemical accumulation, Geographical location, Altitude, Quantitative phytochemical analysis, Senna italic

(C) 2018 The Authors. Published by Innovare Academic Sciences Pvt Ltd. This is an open access article under the CC BY license (http://creativecommons.org/licenses/by/4.0/) DOI: http://dx.doi.org/10.22159/ijpps.2018v10i2.22950

\section{INTRODUCTION}

Worldwide, medicinal plants continue to be relied upon as solutions to health problems administered through traditional medicine practices $[1,2]$. Medicinal plants also offer a new scope of research in disease treatment based on their alluded safety and accessibility properties [3]. The medicinal value of herbal remedies has been attributed to their bioactive phytochemical constituents such as flavonoids, tannins, terpenoids, alkaloids, anthraquinones, saponins and other secondary metabolites [4], which have the ability to induce biological responses in other organisms that include enzyme inhibition [5]. Some of the medicinal plants used as herbal remedies are widely distributed along different locations with varying environmental parameters such as altitudes and soil types. Many environmental factors can act singly or interact on medicinal plants to affect the productivity of its secondary metabolites.

Amongst environmental factors that can affect the phytochemical compositions of plants is the geographical location of growth [6,7]. Geographical locations are different from each other, with others being costal and others being inland. However, to lend a better description in the differences in these locations, altitude may come in handy. Altitude is regarded as the height of the geographical location in relation to the sea level and is one of the parameters usually used in the description of geographical locations [8].

Senna italica, a member of the Fabaceae family, is one medicinal plant widely distributed in the Limpopo province of South Africa and is well known for its therapeutic properties [9-11]. However, it has not been establishing whether the geographical location has any effect on the quantity of its phytochemicals. The current study was aimed at the comparison of the quantity of phytochemicals of the leaves of S. italica collected from different areas in Limpopo province, South Africa.

\section{MATERIALS AND METHODS}

\section{Plant samples collection and preparation of extracts}

The leaves of S. italica Mill, subspecies arachoides (Burch) Lock (UNIN 11129) were collected from four districts in the Limpopo province of South Africa [namely; Capricorn district (Bolahlakgomo village, $927 \mathrm{~m}$ above sea level), Sekhukhune district (Apel cross village, $1420 \mathrm{~m}$ above sea level), Vhembe district (Mutale village, $606 \mathrm{~m}$ above sea level) and Waterberg district (Mosesetjane village, $1099 \mathrm{~m}$ above sea level)] during the summer of 2016. The districts from which the samples were collected are shown in fig. 1 . The leaves were then dried at room temperature and ground to a powder using a coffee grinder (Mellerware, South Africa). The ground leaf samples $(5 \mathrm{~g})$ of $S$. italica were then extracted with $50 \mathrm{ml}$ of $n$-hexane, dichloromethane, acetone and methanol by cold maceration using a non-sequential exhaustive extraction procedure. The resultant extracts were filtered and the solvents evaporated under a stream of air. The dried extracts were stored in the dark until further use.

\section{Experimental procedure}

The extracts of the leaf samples of $S$. italica collected from different areas were analysed and compared for total phenolic content, total flavonoid content, total tannin content and total saponin content, as described below. 


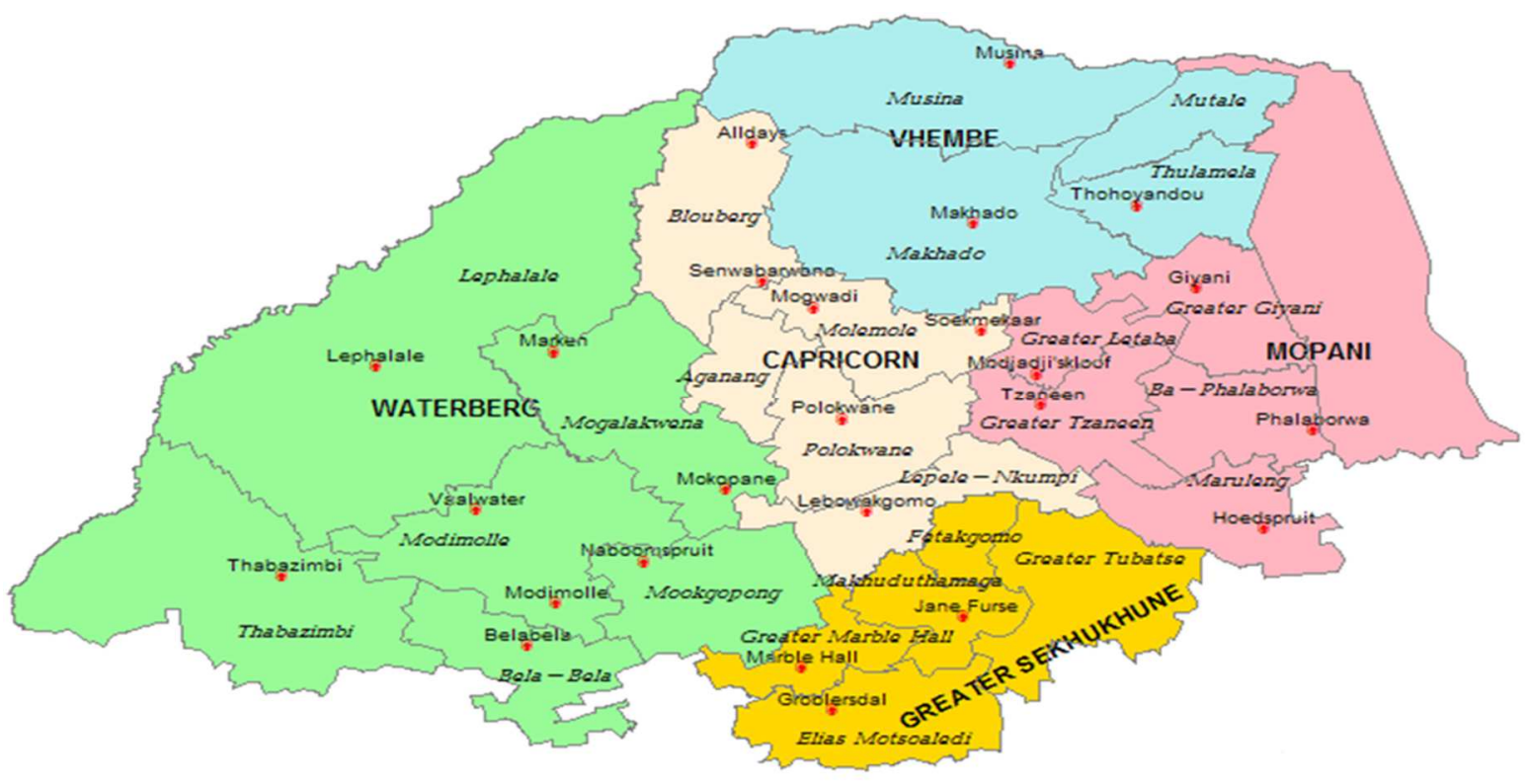

Fig. 1: The map of Limpopo province indicating the four districts (Capricorn, Sekhukhune, Vhembe and Waterberg) from which samples were collected (www.capeinfo.com/blogs/wp-content/blogs.dir/akela/files/2009/05/limpopo_dlghgovza.gif)

\section{Determination of total phenolic content}

The quantity of total phenolic compounds from the leaf extracts of $S$. italica collected from four districts in the Limpopo province of South Africa was determined by the Folin-Ciocalteu assay as described by Tambe and Bhambar [12]. Standard solutions of gallic acid (20,40,60, $80,100 \mu \mathrm{g} / \mathrm{ml}$ ) were prepared from which, $1 \mathrm{ml}$ of each of the gallic acid solutions was added into a $25 \mathrm{ml}$ volumetric flask to create a reaction mixture. Then, $1 \mathrm{ml}$ of Folin-ciocalteu phenol reagent (SigmaAldrich, St. Louis, Missouri, United States) was added with well shaking. After $5 \mathrm{~min}, 10 \mathrm{ml}$ of $7 \%$ Sodium carbonate $\left(\mathrm{Na}_{2} \mathrm{CO}_{3}\right)$ solution was added to the mixture and the volume was made up to $25 \mathrm{ml}$ with distilled water. The solution was then incubated for $90 \mathrm{~min}$ at room temperature and the absorbance was recorded at $550 \mathrm{~nm}$ with an ultraviolet/visible (UV/vis) spectrophotometer (CECIL CE 1021, Cecil Instruments Limited, UK). Solutions of n-hexane, dichloromethane, acetone and methanol leaf extracts of $S$. italica were prepared and absorbance read in the same manner as described above. The total phenol content of the extracts was expressed as mg of gallic acid equivalence/g of extract (mg GAE/g).

\section{Determination of total tannin content}

The quantity of total phenolic compounds from the leaf extracts of $S$. italica collected from four districts in the Limpopo province of South Africa was determined by the Folin-Ciocalteu assay as described by Tambe and Bhambar [12]. Standard solutions of gallic acid $(20,40$, $60,80,100 \mu \mathrm{g} / \mathrm{ml}$ ) from which, $0.5 \mathrm{ml}$ of each of the different gallic acid solutions were added to a $50 \mathrm{ml}$ volumetric flask to which, was added $2.5 \mathrm{ml}$ of Folin-Ciocalteu phenol reagent (Sigma-Aldrich, St. Louis, Missouri, United States), $1 \mathrm{ml}$ of $35 \% \mathrm{Na}_{2} \mathrm{CO}_{3}$ solution and diluted to $50 \mathrm{ml}$ with distilled water. The resultant solution was well shaken and kept at room temperature for $30 \mathrm{~min}$. Then absorbance of the solutions was measured at $725 \mathrm{~nm}$ with an UV/vis spectrophotometer (CECIL CE 1021, Cecil Instruments Limited, UK). Solutions of hexane, dichloromethane, acetone and methanol leaf extracts of the Senna italica were prepared and absorbance read in the same manner as described above. The phenol content of these extracts was expressed as $\mathrm{mg}$ of gallic acid equivalence/g of extract (mg GAE/g).

\section{Determination of total flavonoid content}

Total flavonoid content was measured by the aluminium chloride colourimetric assay as described by Tambe and Bhambar [12]. The reaction mixture consists of $1 \mathrm{ml}$ of extract and $4 \mathrm{ml}$ of distilled water was taken in a $10 \mathrm{ml}$ volumetric flask. To the flask, $0.30 \mathrm{ml}$ of
$5 \%$ sodium nitrite was treated and after $5 \mathrm{~min}, 0.3 \mathrm{ml}$ of $10 \%$ aluminium chloride was mixed. After $5 \mathrm{~min}, 2 \mathrm{ml}$ of $1 \mathrm{M}$ Sodium hydroxide was treated and diluted to $10 \mathrm{ml}$ with distilled water. Reference standard solutions of quercetin $(20,40,60,80$ and 100 $\mu \mathrm{g} / \mathrm{ml}$ ) were prepared in the same manner as described above. Then absorbance for test and standard solutions were determined against the reagent blank at $510 \mathrm{~nm}$ with an UV/vis spectrophotometer (CECIL CE 1021, Cecil Instruments Limited, UK). The total flavonoid content was expressed as mg of quercetin (Sigma-Aldrich, St. Louis, Missouri, United States) equivalence/g of extract (mg QE/g).

\section{Determination of total saponin content}

Estimation of total saponin content was determined based on vanillinsulphuric acid colorimetric reaction as described by Senguttuvan et al. [13]. About $50 \mu \mathrm{l}$ of plant extract was added to $250 \mu \mathrm{l}$ of distilled water. To this, about $250 \mu \mathrm{l}$ of vanillin reagent (Sigma-Aldrich, St. Louis, Missouri, United States) ( $800 \mathrm{mg}$ of vanillin in $10 \mathrm{ml}$ of $99.5 \%$ ethanol) was added. Then $2.5 \mathrm{ml}$ of $72 \%$ sulphuric acid was added and it was mixed well. This solution was kept in a water bath at $60^{\circ} \mathrm{C}$ for $10 \mathrm{~min}$. After $10 \mathrm{~min}$, it was cooled in ice-cold water and the absorbance was read at $544 \mathrm{~nm}$ with an UV/vis spectrophotometer (CECIL CE 1021, Cecil Instruments Limited, UK). The values were expressed as diosgenin (Sigma-Aldrich, St. Louis, Missouri, United States) equivalents/g extract (mg DE/g) derived from a standard curve.

\section{Statistical analysis}

The significant differences of phytochemical quantities in the leaf samples from different geographical locations were determined by analysis of variance (ANOVA) using the SPSS (version 12.00) statistical package. The difference in phytochemical quantity values was considered as statistically significant at $p<0.05$, main data were expressed as mean \pm SD.

\section{RESULTS}

The extracts of the leaf samples of S. italica from four districts in Limpopo province of South Africa were analyzed for total phenolic contents, tannins, flavonoids and saponins and the results are presented in tables $1,2,3$ and 4, respectively. The mean values of phytochemicals in different extracts of the samples were added together to obtain total values per sample from each area, for each specific phytochemical group, and statistically compared. The results showed some differences in the quantities of total phenolics, tannins, flavonoids and saponins amongst the leaf samples collected from four districts in Limpopo province. 
Total phenolic content expressed as mg GAE/g extract, was found in highest amounts in leaf samples from Waterberg district compared to samples from other districts. Total tannin content also expressed as mg GAE/g extract, was in highest amounts in the Vhembe district leaf samples compared to samples from other districts. Total flavonoid content expressed as $\mathrm{mg} \mathrm{QE} / \mathrm{g}$ extract was found in highest amounts in the leaf samples from Waterberg district compared to samples from other districts. Total saponin content, expressed as mg DE/g extract was in highest amounts in the Vhembe district leaf samples compared to samples from other districts.

Table 1: Total phenolic content (mg GAE/g extract) in the extracts of the leaf samples of $S$. italica from four districts in limpopo province, South Africa

\begin{tabular}{|c|c|c|c|c|c|}
\hline District & Hexane extracts & Dichloromethane extracts & Acetone extracts & Methanol extracts & Total (mg GAE/g) \\
\hline Capricorn & - & $0.480 \pm 0.148$ & $0.364 \pm 0.012$ & $1.31 \pm 0.053$ & $2.15^{\mathrm{a}^{*}}$ \\
\hline Sekhukhune & - & $0.487 \pm 0.006$ & $0.335 \pm 0.009$ & $1.69 \pm 0.006$ & $2.51^{\mathrm{b}^{*}}$ \\
\hline Vhembe & - & $0.525 \pm 0.00$ & $0.505 \pm 0.006$ & $2.96 \pm 0.029$ & $3.99^{c^{*}}$ \\
\hline Waterberg & - & $0.590 \pm 0.012$ & $0.534 \pm 0.009$ & $3.61 \pm 0.006$ & $4.73^{\mathrm{d}^{*}}$ \\
\hline
\end{tabular}

$\mathrm{a}^{*}, \mathrm{~b}^{*}, \mathrm{c}^{*}, \mathrm{~d}^{*}$ : values with different alphabetical letters are significantly different, i.e., $p<0.05$; results are mean $\pm \mathrm{SD}$ with $\mathrm{n}=3$ ( $-:$ not determined)

Table 2: Total tannin content (mg GAE/g extract) in the extracts of the leaf samples of $S$. italica from four districts in Limpopo province, South Africa

\begin{tabular}{llllll}
\hline District & Hexane extracts & Dichloromethane extracts & Acetone extracts & Methanol extracts & Total (mg GAE/g) \\
\hline Capricorn & - & - & $0.767 \pm 0.285$ & $8.23 \pm 0.235$ \\
Sekhukhune & - & - & $0.221 \pm 0.135$ & $30.8 \pm 0.358$ \\
Vhembe & - & - & $1.09 \pm 0.223$ & $31.0^{\mathrm{b}^{*}}$ \\
Waterberg & - & - & $0.531 \pm 0.319$ & $40.7 \pm 1.48$ & $37.5 \pm 0.184$ \\
\hline
\end{tabular}

$\mathrm{a}^{*}, \mathrm{~b}^{*}, \mathrm{c}^{*}, \mathrm{~d}^{*}$ : values with different alphabetical letters are significantly different, i.e., $p<0.05$; results are mean $\pm \mathrm{SD}$ with $\mathrm{n}=3$ (-: not determined)

Table 3: Total flavonoid content (mg QE/g extract) in the extracts of the leaf samples of $S$. italica from four districts in Limpopo province, South Africa

\begin{tabular}{llllll}
\hline District & Hexane extracts & Dichloromethane extracts & Acetone extracts & Methanol extracts & Total (mg QE/g) \\
\hline Capricorn & $0.862 \pm 0.030$ & $0.962 \pm 0.053$ & $1.32 \pm 0.054$ & $1.17 \pm 0.123$ \\
Sekhukhune & $0.753 \pm 0.074$ & $0.853 \pm 0.139$ & $0.710 \pm 0.044$ & $2.18 \pm 0.277$ \\
Vhembe & $0.584 \pm 0.108$ & $0.684 \pm 0.159$ & $0.949 \pm 0.133$ & $3.19 \pm 0.066$ \\
Waterberg & $0.924 \pm 0.199$ & $1.02 \pm 0.202$ & $0.941 \pm 0.057$ & $3.33 \pm 0.175$ \\
\hline
\end{tabular}

$\mathrm{a}^{*}, \mathrm{~b}^{*}, \mathrm{c}^{*}, \mathrm{~d}^{*}$ : values with different alphabetical letters are significantly different, i.e., $p<0.05$; results are mean $\pm \mathrm{SD}$ with $\mathrm{n}=3$

Table 4: Total saponin content (mg DE/g extract) in the extracts of the leaf samples of $S$. italica from four districts in Limpopo province, South Africa

\begin{tabular}{|c|c|c|c|c|c|}
\hline District & Hexane extracts & Dichloromethane extracts & Acetone extracts & Methanol extracts & Total (mg DE/g) \\
\hline Capricorn & $0.167 \pm 0.008$ & $0.235 \pm 0.008$ & $0.063 \pm 0.364$ & $0.232 \pm 0.051$ & $0.697^{\mathrm{a}^{*}}$ \\
\hline Sekhukhune & $0.175 \pm 0.166$ & $0.253 \pm 0.166$ & $0.096 \pm 0.082$ & $0.538 \pm 2.42$ & $1.06^{\mathrm{b}^{*}}$ \\
\hline Vhembe & $0.321 \pm 0.194$ & $0.394 \pm 0.194$ & $0.164 \pm 0.194$ & $0.637 \pm 1.84$ & $1.52^{\mathrm{d}^{*}}$ \\
\hline Waterberg & $0.235 \pm 0.004$ & $0.303 \pm 0.048$ & $0.162 \pm 0.048$ & $0.536 \pm 1.92$ & $1.24 \mathrm{c}^{*}$ \\
\hline
\end{tabular}

$a^{*}, b^{*}, c^{*}, d^{*}$ : values with different alphabetical letters are significantly different, i.e., $p<0.05$; results are mean $\pm S D$ with $n=3$

The total quantities of phenolic, tannins, flavonoids and saponins were added together to obtain the total phytochemical content of the leaf samples of $S$. italica from each of the four districts in Limpopo province, South Africa and the results are presented in table 5. The results showed that the highest amount in phytochemical content was recorded with leaf samples from the Vhembe district $(52.7 \mathrm{mg} / \mathrm{g}$ extract), followed by leaf samples from Waterberg $(50.2 \mathrm{mg} / \mathrm{g})$ and Sekhukhune $(39.1 \mathrm{mg} / \mathrm{g})$ districts, respectively. The least amount of total phytochemical content was recorded with the leaf samples from the Capricorn district $(16.1 \mathrm{mg} / \mathrm{g})$. The percentages of total phenolic, tannins, flavonoids and saponins were calculated in relation with the total phytochemical content for samples from each district and the percentages were averaged to estimate the distribution pattern of phytochemicals within the leaves of $S$. italica from Limpopo province of South Africa, and the results are shown in fig. 2 . The phytochemical composition of the leaves of $S$. italica from Limpopo province appears to be dominated by tannins at $72.5 \%$ on average.

Table 5: Total phytochemical content of the leaf samples of $S$. italica from four districts in limpopo province, South Africa

\begin{tabular}{ll}
\hline District & Total phytochemical content (mg/g extract) \\
\hline Capricorn & $16.1^{\mathrm{a}^{*}}$ \\
Sekhukhune & $39.1^{\mathrm{b}^{*}}$ \\
Vhembe & $52 . \mathrm{d}^{\mathrm{d}^{*}}$ \\
Waterberg & $50.2^{\mathrm{c}^{*}}$ \\
\hline
\end{tabular}

$\mathrm{a}^{*}, \mathrm{~b}^{*}, \mathrm{c}^{*}, \mathrm{~d}^{*}$ : values with different alphabetical letters are significantly different, i.e., $p<0.05$; results are the sum of different total phytochemical groups of plant sample collected at a particular location. 


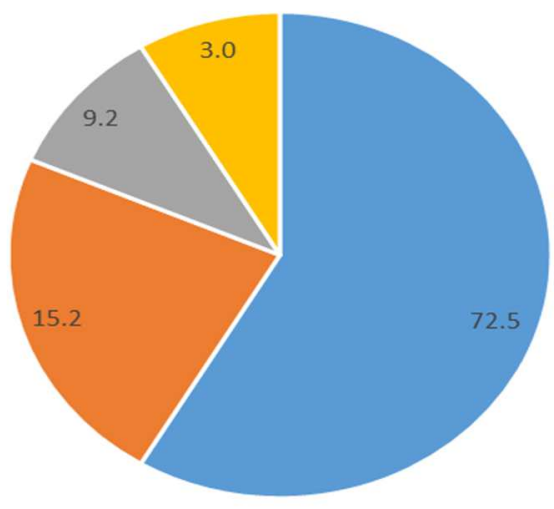

$=\operatorname{tannins}(72.5 \%) \quad$ m flavonoids $(15.2 \%) \quad$ m phenolics $(9.2 \%) \quad$ saponins $(3.0 \%)$

Fig. 2: The average phytochemical distribution pattern within the leaves of $S$. italica from Limpopo province, South Africa

\section{DISCUSSION}

Quantification of phytochemicals within the samples of plant parts from different locations will help in establishing whether the geographical location has an effect on the phytochemical composition of the medicinal plant under current study. It also provides knowledge on the suitable habitation area that affords optimum concentrations or quantities of specific active ingredients [14]. The dose-dependent manner has been shown in the biological activities of many Medicinal plants [15], hence the importance of harvesting medicinal plants in locations where they possess high accumulation of phytochemicals for usage in traditional medicine. In the current study, the quantities of phytochemicals within similar solvent extracts of the leaf samples of $S$. italica collected from the different areas in Limpopo province (South Africa) were found to be statistically different at $\mathrm{p}<0.05$, suggesting that they were affected by the location conditions. However, the effect appears to be phytochemical group specific since the high accumulation of the different phytochemicals were not recorded in one location. Total phenolic and flavonoid contents were found in highest amounts in leaf samples from Waterberg district, whereas total tannin and saponin contents were found in highest amounts in samples from Vhembe district.

The addition of total phenolic, tannins, flavonoids and saponins of samples enabled the determination of the total phytochemical content of leaf samples from each district. The calculated total phytochemical content gives a clear indication of the district area with high overall accumulation of phytochemicals, and in this study leaf sample of $S$. italica from Vhembe district showed high overall amounts of phytochemicals. From the calculated total phytochemical content, the relative percentages of each phytochemical group were determined. On average, the leaf samples of $S$. italica from the four districts in Limpopo province of South Africa appear to be rich in tannins, with moderate possession of flavonoids and poor accumulation of saponins. Thus, calculation of total phytochemical content also enables the determination of the distribution pattern of phytochemicals within plant parts.

These results of the current study are in agreement with the findings of the previous study by Nchabeleng et al. [6], where the differences in the phytochemical composition of wild bush tea (Athrixia phylicoides DC) growing at locations differing in altitude was demonstrated. The four areas from which the leaf samples of $S$. italica were collected are of different altitudes and soil types. These environmental factors, altitude and soil type, were reported through previous studies to influence the accumulation of phytochemicals in medicinal plants $[14,16,17]$.

\section{CONCLUSION}

The results of the current study indicate the difference in the quantities of the investigated phytochemicals of the leaf samples of S. italica collected from different areas in Limpopo province of South
Africa. The findings of the study thus suggest that geographical location has an effect on the accumulation of phytochemicals in the leaves of S. italica.

\section{ACKNOWLEDGEMENT}

The authors would like to acknowledge the Department of Biochemistry at Sefako Makgatho Health Sciences University for the facilities used to do the study and Dr Bronwyn Egan from the Department of Botany for the taxonomic authentication of the plant species. The study was financially supported through the DHET Research Development Grant (RDG: GOLOLO) funding.

\section{AUTHORS CONTRIBUTIONS}

Gololo: conceptualization of the study, data analysis and writing of the manuscript.

Mapfumari: data collection and analysis, as well as the writing of the manuscript.

Mogale: writing of the manuscript.

\section{CONFLICT OF INTERESTS}

The authors declare no conflict of interests

\section{REFERENCES}

1. Ogundipe T, Ajayi GO. History and practice of traditional medicine and its challenges. In: Odugbemi $\mathrm{T}$. editors. A Textbook of Medicinal Plants from Nigeria, Lagos: University of Lagos Press; 2008. p. 19-24.

2. Van Wyk BE, Van Oudsthoorn B, Gericke N. Medicinal plants of South Africa. Briza Publications (Pretoria); 1997.

3. Rahmani AH, Aly SM. Nigelia sativa and its active constituents thymoquinone shows pivotal role in the diseases prevention and treatment. Asian J Pharm Clin Res 2015;8:48-53.

4. Saxena M, Saxena J, Nema R, Singh D, Gupta A. Phytochemistry of medicinal plants. J Pharmacogn Phytochem 2013;1:168-82.

5. Kiranmayi P. Is bioactive compounds in plants acts as antinutritional factors? Int J Curr Pharm Res 2014;6:36-8.

6. Nchabeleng L, Mudau FN, Mariga IK. Effects of the chemical composition of wild bush tea (Athrixia phylicoides DC.) growing at locations differing in altitude, climate and edaphic factors. J Med Plants Res 2012;6:1662-6.

7. Pawson IG, Jest C. The high-altitude areas of the world and their cultures. In: Baker PT. editors. The Biology of HighAltitude Peoples. Cambridge: University Press (UK); 1978. p. 17-45.

8. Newman DJ, Cragg GM. Natural products as sources of new drugs over the 30 y from 1981 to 2010. J Nat Prod 2012;75:311-35.

9. Masoko P, Gololo SS, Mokgotho MP, Eloff JN, Howard RL, Mampuru LJ. Evaluation of the antioxidant, antibacterial and 
antiproliferative activities of the acetone extract of the roots of Senna italica (Fabaceae). Afr J Tradit Complementary Altern Med 2010;7:138-48.

10. Lekganyane MA, Matsebatlela TM, Howard RL, Shai LJ, Masoko $P$. The phytochemical, antibacterial and antioxidant activity of five medicinal plants against the wound-infecting bacteria. Afr J Biotechnol 2012;11:13210-9.

11. Tshikalange TE, Meyer JJM, Husein AA. Antimicrobial activity, toxicity and the isolation of bioactive compounds from plants used to treat sexually transmitted diseases. J Ethnopharmacol 2005;96:515-9.

12. Tambe VD, Bhambar RS. Estimation of total phenol, tannin, alkaloid and flavonoids in Hibiscus tiliaceus Linn. Wood extracts. Res Rev: J Pharmacogn Phytochem 2014;2:41-7.

13. Senguttuvan J, Paulsamy S, Karthika K. Phytochemical analysis and evaluation of leaf and root parts of medicinal herb,
Hypochaeris radicata $\mathrm{L}$. for in vitro antioxidant activities. Asian Pac J Trop Biomed 2014;4:S359-67.

14. Inbathamizh L, Padmini E. Effect of geographical properties on the phytochemical composition and antioxidant potential of Moringa oleifera flowers. BioMedRx 2013;1:239-47.

15. Morris T, Stables M, Hobbs A, de Souza P, Colville-Nash P, Warner $\mathrm{T}$, et al. Effects of low-dose aspirin on acute inflammatory responses in humans. J Immunol 2009;183:2089. 96.

16. Ross IA. Medicinal plants of the world: Vol. 1: Chemical Constituents, Traditional and Medicinal uses. $2^{\text {nd }}$ ed. New York: Springer-Science+Busines Media, LLC; 2003.

17. Mahdavi M, Jouri MH, Salehi MD, Motevalizadeh A. The effects of ecological factors of the site on quality and quantity of the essence from Phlomis cancellata Bunge in Mazandaran province (Iran). Int J Agric Crop Sci 2014;7:1478-84. 